\title{
Morphometry of the Nasolabial Complex in Adult Indian Population
}

\author{
Ankit Srivastav, B.V. Murlimanju, Latha V. Prabhu, K.U. Prashanth, \\ K.M. Sukritha \\ Department of Anatomy, Manipal University, Centre for Basic Sciences, Kasturba Medical College, Bejai \\ Campus, Mangalore - 575004, India.
}

\section{Introduction}

Anthropometry of lip-nose complex has been extensively studied for European population. ${ }^{1-6}$ However, corresponding studies in case of Indian population are very scarce. ${ }^{3-9}$ Hence anthropometric study of lip-nose complex was undertaken. This study involves comparison with available data from literature. The objective was to study the morphometry of the nasolabial complex in Indian population.

\section{Methods}

The procedure of measuring the lip-nose complex was explained to each individual resulting in the accurate measurements due to lack of anxiety on the part of individual. The morphometry was done on 100 adults (age range: $18-45 \mathrm{yrs}$ ). Among them 44 were males and 56 were females. The parameters like vertical lip height, cupids bow width, total width of the mouth, columellar height, columellar width, nasal width and dome height were measured. The measurements were repeatedly taken for each individual to ensure the accuracy. The points of lip-nose complex were marked using marking pen (Fig. 1) and the linear measurements were taken using digital vernier caliper. The vertical height of the lip was from the columellar base to cupids bow peak. This parameter was chosen against base of columella to tubercle since it has significance in cleft lip surgery. The cupids bow width was measured from philtrum peak to peak. The total width of mouth was the commissure to commissure distance.

\section{Results}

The measurements were statistically analysed (arithmetic mean and standard deviation were calculated) and tabulated (Table 1). The results were compared with available data for Caucasions, blacks and Chinese (Table 2).

\section{Discussion}

The present study establishes the basal values for various parameters of lip-nose complex of the Indian population. Since standard deviations for Caucasions and blacks being not available only mean values are compared. The present study reveals that vertical lip height, cupids bow width, total width of the mouth and columellar height were more amongst males compared to females. The same pattern is seen with Caucasions and blacks. Columellar height is more in male as well as in female adult Caucasions compared to Indians and blacks. Columellar height is lowest amongst Chinese compared to other races.

The Indian males as well as females have lowest columellar width compared to Caucasions and blacks, which again indicates a change in growth pattern. There is a resemblance in columellar width between Chinese and Indians. Nasal width is more amongst Indian males compared to Indian females. Nasal width is maximum amongst blacks compared to Indians and Caucasions. Indian males have larger values for columellar height and columellar width. Vertical height of the lip is more amongst Indian males compared to females. Adult Caucasions have more vertical height of the lip compared to Indians and blacks and Indian males and females have the lowest vertical height of the lip.

Cupid's bow width is same amongst adult InIndian males have wide oral commissure compared to females at all age groups. Oral commissure is smallest amongst Indian males and females at all age groups compared to Caucasions and blacks. Adult male and female blacks have wide oral commissure compared to Caucasions and blacks. Dome height is more in Indian adult males compared to females. The data was not available for Caucasions and blacks for comparison. Indian males and females differ significantly in certain parameters from that of Caucasions and blacks but shows resemblance to Chinese. For years together the anthropometric measurements for surgical reconstructions are based on basic values for western population 
resulting in the time of surgical repair being based on western growth patterns, which actually differs for Indians. This has not been given a serious thought. Our study has been conducted to generate Indian data.

[1]. Farkas LG, Lindsay, Cleft Craft, 1976;1:36-8.

\section{References}

[2]. Farkas LG, Cheung GCK. Nostril asymmetry: Microform of cleft lip palate? An anthropometrical study of healthy North American Caucasians. Cleft Palate J 1979;16:351.

[3]. Shah M, Verma IC, Mahadevan S, Puri RK. Facial anthropometry in Newborns in Pondicherry. Indian J Paediatrics 1991;25:259-63.

[4]. Farkas LG, Posnick JC, Hreczko, T.M., and Pron, G.E. Growth patterns of the nasolabial region : A morphophetric study. Cleft Palate Craniofac J 1992;29:318.

[5]. Farkas LG, Hajnis K, Posnick JC. Anthropometric and anthroposcopic findings of the nasal and facial region in cleft patients before and after primary lip and palate repair. Cleft Palate Craniofac J 1993;30:1.

[6]. Farkas LG. Anthropometry of the Head and Face, $2^{\text {nd }}$ Ed. New York : Raven Press 1994.

[7]. Farkas LG, Tompson B, Philips J, Katic M, Cornfoot L. Comparison of Anthropometric and Cephalometic Measurements of the adult Face. Cleft Palate Craniofac 1999;5:10-8.

[8]. Mulliken JB, Burvin R, Leslie G, Farkas LG, Repair of bilateral complete cleft lip: Intraoperative Nasolabial Anthropometry, Plastic and Reconstructive Surgery 2001;107:307-14.

[9]. Prasad NN, Reddy D. Anthropometry: Lip-Nose Complex. Indian Journal of Plastic Surgery 2001;34:3-8.
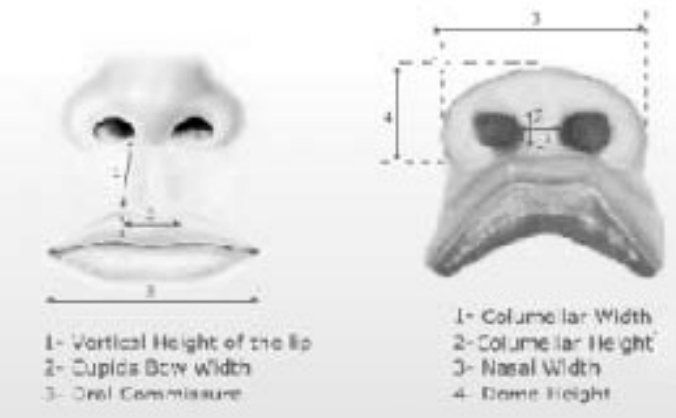

Fig. 1 Diagram showing the details of measurements of the present study

Table 1 Comparison of nasolabial morphometry among males $(n=44)$ and females $(n=56)$

\begin{tabular}{ccc}
\hline values in $\mathrm{cm}$ & male & female \\
\hline vertical lip height* & $12.9 \pm 2.2$ & $10.5 \pm 2.2$ \\
cupids bow width* & $11.5 \pm 2.1$ & $10 \pm 1.5$ \\
total width of the mouth* & $52 \pm 7.1$ & $48.7 \pm 6.9$ \\
columellar height* & $10.9 \pm 2.5$ & $8.8 \pm 2.4$ \\
columellar width & $8.1 \pm 1$ & $8.1 \pm 1.1$ \\
nasal width & $32.1 \pm 3.1$ & $31.6 \pm 3.7$ \\
dome height & $18 \pm 6.8$ & $18.2 \pm 3$ \\
\hline
\end{tabular}

values are mean $\pm \mathrm{SD}$, statistical significance (independent t-test) ${ }^{*} \mathrm{p}<0.05$

Table 2 Showing the racial variability of the parameters among various populations

\begin{tabular}{|c|c|c|c|c|c|c|c|c|c|c|}
\hline & $\begin{array}{l}\text { Present } \\
\text { (Indian) }\end{array}$ & study & $\begin{array}{l}\text { West } \\
\text { Indian } \\
\end{array}$ & & Chinese & & Caucasions & & Blacks & \\
\hline values in $\mathrm{cm}$ & M & $\mathrm{F}$ & M & $\mathrm{F}$ & $\mathrm{M}$ & $\mathrm{F}$ & M & $\mathrm{F}$ & M & $\mathrm{F}$ \\
\hline vertical lip height* & 12.9 & 10.5 & 16.2 & 14.2 & 16 & 13 & 22 & 15 & 21 & 21 \\
\hline cupids bow width* & 11.5 & 10 & 11.7 & 11.8 & 12 & 11 & 15 & 13 & 12 & 13 \\
\hline total width of the mouth* & 52 & 48.7 & 53.5 & 47 & 56 & 53 & 63 & 57 & 72 & 57 \\
\hline columellar height* & 10.9 & 8.8 & 9.8 & 8.6 & 6 & 5 & 13 & 11 & 10 & 9 \\
\hline nasal width & 32.1 & 31.6 & 32.3 & 30.5 & 43 & 39 & 36 & 33 & 44 & 45 \\
\hline dome height & 18 & 18.2 & 20.4 & 16.9 & - & - & - & - & - & - \\
\hline
\end{tabular}

